\title{
Efficient Manufacturing \& Logistics in Indian E- Commerce Industry and Its Effect on Customer Satisfaction
}

\author{
Anup Sharma ${ }^{1}$, Akhil Babu ${ }^{2}$, Blesly Panavila², Sapna Raghuvanshi ${ }^{2}$, MD Yunus Pathan ${ }^{2}$ \\ ${ }^{1}$ Assistant Professor, Lovely Professional University; \\ ${ }^{2}$ MBA Scholar, Lovely Professional University
}

\begin{abstract}
In this paper, the topic "Efficient manufacturing and logistics in Indian e-commerce industries and its effect on customer satisfaction" refers to one of the famous method (JIT - Just in time) used in manufacturing along with labor, material, and other inputs. The JIT role in Indian e-commerce industry is increasing, and awareness of Indian e-commerce industry enhances productivity of online retailers. It generates high level of satisfaction in customers, availing offline as well as online e-commerce services. JIT also contributes in improving physical distribution quality. Internal and external environment affects logistics and supply chains. From customer point of view, demand fulfillment using JIT method, clarity of production planning, sourcing and logistics are vital in Indian e-commerce industry.
\end{abstract}

Keywords: Logistics, Supply chain, Covid-19

\section{Introduction}

Increasing business competitiveness giving more reliable options for the customers to choose the products, at this point of time e-commerce business is raising its standards with advanced manufacturing processes and integrated logistics systems. We need to study how these efficient processes changing the level of customer satisfaction. A country like India, with rapid growth in its economy, the buying intentions of the people are changing according to the new technology and trends around the world.

Globalization all around the world, increasing the communication between the people and increasing the desire according to the perception of the people, all these would affect buying options of the customer. From the past to present, updates in the manufacturing and logistics sectors have gone a long way from traditions set of principles to Integrated logistics.

Introduction of Just-In-time, Flexibility Logistics, Green Logistics, having its significant effect on the production process and warehousing etc., and giving more appropriate results for the firms and as well as for the customer. Were people with different socio-culture, preference, and routine, differs more than the rest of the world. How these practices are working and where it was lagging. With the implementation of these practices by the Indian industry what kind of results are they getting and how much more can it be improved. How the practices from the other parts of the world influencing India's market. Does it create any negative impacts through the reviewing of the papers from the past, which is quite related to efficient logistics and manufacturing practices and comparing with feedback from the customer about customer behavior? The role of Technology, Economic growth, Flexibility and reliability, operations aspects, automation, and finally human psychology, we will study in the project.

\section{Review of Literature}

Thomas J. Goldsby, 2008. Electronic Logistics Service Quality

Its Impact on the Customer's Purchase Satisfaction and Retention" which deals with internet retailing or ecommerce industries continues to grow rapidly. Several Internet retailers are, however, strolling to retain 
customers due to the high level of competition among company holders.

Rajendran, Shalini \& Wahab, Siti \& Ling, Yeow\& Yun, Lim, 2018. The Impact of Logistics Services On the E-shopper's Satisfaction

This study is helpful for online retailers to identify various ways to improve logistics services, the factors positively influencing the satisfaction level of retailers\& E-commerce shoppers.

Khosla, Madhurinam\& Jumar, Harish, 2017. IOSR Journal of Business and Management Fast growing segments in the Indian market, where the industry has been behind in this to

manufacturing various types of segments, however increased technological combination of internet, mobile penetration, available of low cost and smart technologies implemented in industries

Frimpong, Nadia, 2019. The Role of Logistics Service Providers and E-commerce Companies E-commerce industry in recent years has been a massive growth and this has made customers become online approaches, logistics service providers need to work hand in hand, data collection was analyzed through structural equation modeling using various techniques.

Shashank Rao, Thomas J. Goldsby, Stanley E. Griffies, Deepak Iyenger, 2011. The satisfaction with the physical distribution mainly cost, quality, and customer's purchase satisfaction also extent of customer retention to fulfillment process.

Pei-Ju Wu, Kun-Chen Lin, 2018. E-commerce logistics would be an innovation towards the logistics, ecommerce logistics management needs to linked with internal organization as well as the technical collaboration to create positive operation performance

Jie Yang, Hongming Xie, Guangsheng Yu, Mingyu Liu, 2021. The role of supply chain it to achieve just in time as well as the intelligence which operationalized by production help to assess the effect of logistics and supply chain.

Mark Huson, Dhanajay Nanda, 2015. The impact of performance and just in time which measure most of the technologies, investments, financial condition of an organization, to allow industries reduced the risk and make performance more significant.

Richard E. White, John N, 2011. The importance of customer service to integrating activities which makes the decision process handy, today's manufacturer's needs to enhanced there development of technologies, new technologies brings process, product and information which provides various information which help in logistics and supply chain.

Maj Rundlof, Henrik G. Smith, Ingemar Friese, Riccardo Bommarco, 2015. The market in which investors need to invest shows the their importance for just in time and logistics and supply chain, the growth 75\% enhanced in North America and Europe continents, 82\% involvement of logistics service and supply chain, $75 \%$ in western region.

Sukanya Kunda, Saroj Kumar Datta, 2015. The effects of variable which are depending and independent on e-commerce service quality on consumer decision making process as well the customer satisfaction and the trust on the variable.

Pankaj Dutta, Anurag Mishra, Sachin Khandelwal, Ibrahim Katthawala, 2020. Developed a sustainable logistics system and reverse logistics network for Indian E-commerce market to achieve the target makes more effective and increase the volume of returns.

Kerstin Dobers, Achim Klukas, Wolfganag Lammers, Marc Laux, Gordon Mauer, Marc Schneider, 2010. Green logistics system improves process and decreases the effects on environment with the approaches of various sectors, management, networking, programming, and planning.

Jean-Paul Rodrigue, Brain Slack, Claude Comtois, 2017. Reduction of costs and needs for warehousing facilities, packaging and waste to get benefited with efficient distribution systems and increase the network changes with the reliable time and distribution

Qingyu Zhang, Mark A. Vonderembse, Jeen-Su Lim, 2005. To provide a variety of service to the customer which makes customer more quickly and efficiently to change their decision making process and 
make buy that product within a simulated time, also adjust the inventory according to the customer demands, variety of customer needs various serviced which may differ in price, time, quantity and quality.

Maciej Bielecki, Magdalena Nanczak, 2018. Mass customization which is one of the most important key elements in logistics and supply chain which make product less storage area and storage space, influences less risk, increased in quality, doesn't require special storage system, improved the controlling system, gives the customer variety of option to select suitable product which customer needs.

\section{The Objective:}

- To analyze the effect of JIT and other techniques on Manufacturing and Logistics

- Factors affecting Customer Satisfaction

- Examine the effects of Logistics and Customer Satisfaction

\section{Graphical Analysis \& Interpretation - Online vrs Offline shopping preferences:}

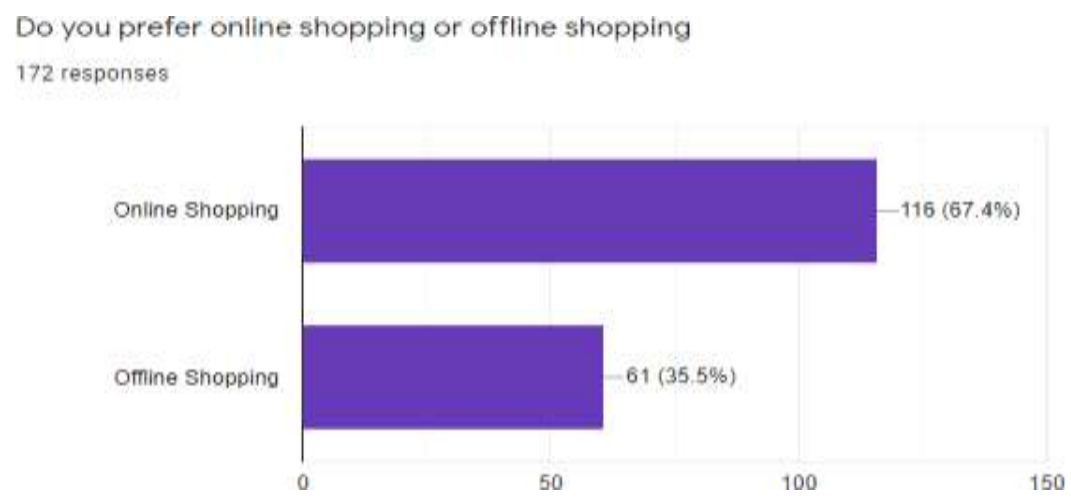

Interpretation: The Above Bar Graph Online \& Offline shopping preference in which $67.4 \%$ refer to do Online Shopping \& 35.5\% believed on Offline Shopping which indicates their own prospective about the shopping \& satisfaction more on Online . (Vivek s Kanade, 2019) To indentify customer needs \& wants based on their profit or on which platform they are more comfortable to buy the product, it may be online or offline.

Effectiveness and safety in Online \& Offline Shopping

Interpretation: The above Pie-chart reveals about the comparison of both online \& offline shopping in

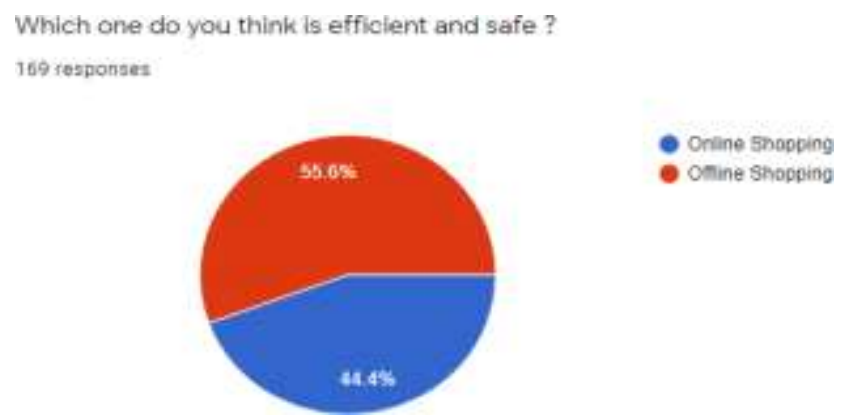

terms of safety and effectiveness. People have felt safer and more efficient in offline shopping because they really feel that offline shopping gave them a clear idea regarding the product because the product Is in front of them rather than on 5-inch screen. (Miniard, 1990) It's totally based on customer intention or purchasing psychological process to make the decision. (Pan, 2007) the relevant information for the product is researched by the customer is based on experience or external environment after the consideration and judgment consumer going to buy.

\section{Preferred Location for Shopping}


Interpretation: The Bar Graph shows about the customers preferred location which they are more satisfied to buy Products online \& offline. As per the survey, most of them prefer Flipkart (Offline) which is 50\%\%.

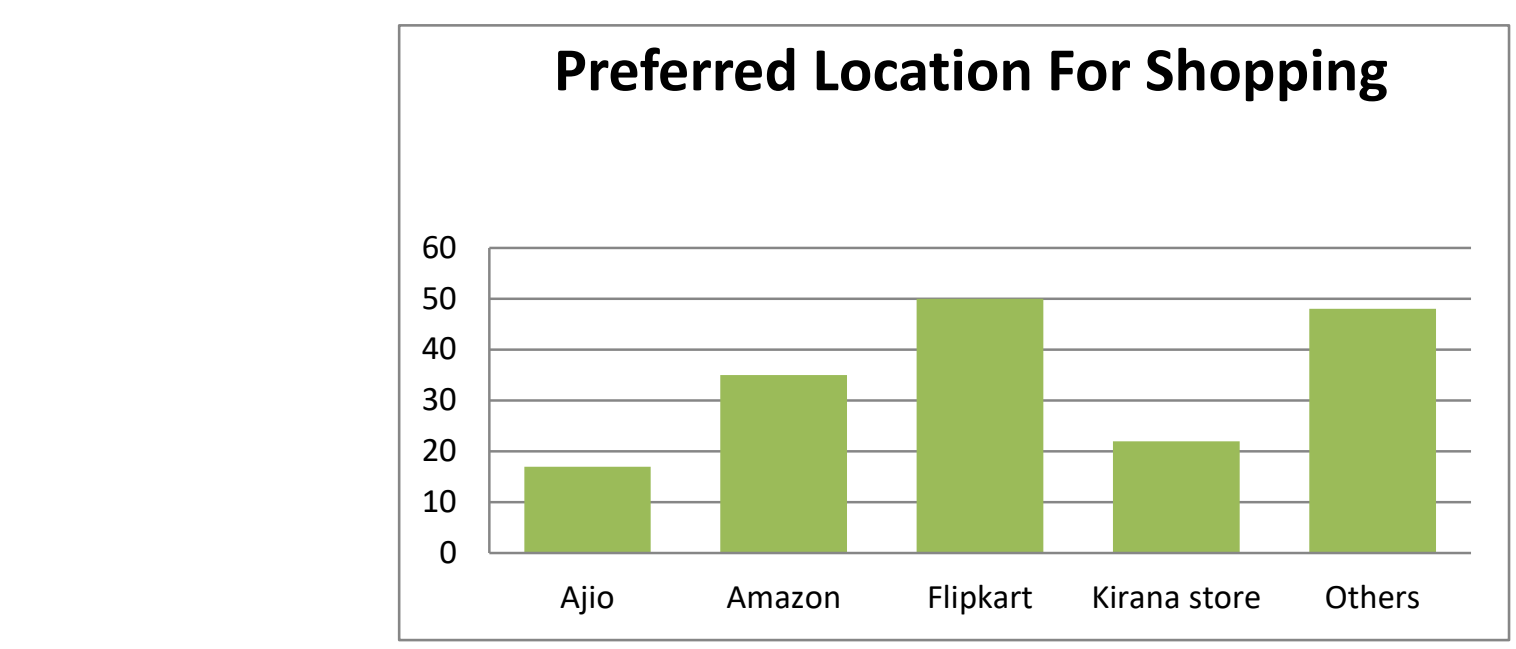

Source: Primary data

Amazon is also having 35\% and second in the charts. In Online Mode, People preferred Ajio i.e. about $17 \%$. Others also have $48 \%$ of people shopping in it. (Nishad Nawaz, M Phil, Wafa Ms, Ali Yaqoob, 2014) technology filled the gap between state to state, cities to cities, people to people based on internet shortened the distance, online shopping has similar tastes \& accessibility, so consumer get the product from anywhere around the world and it can be access 24/7. Mainly in India customer prefer to buy on Flipkart and e- tailer, brand image and fair policies.

How much concerned you are about the product reviews (or customer feedback for offline) while buying?

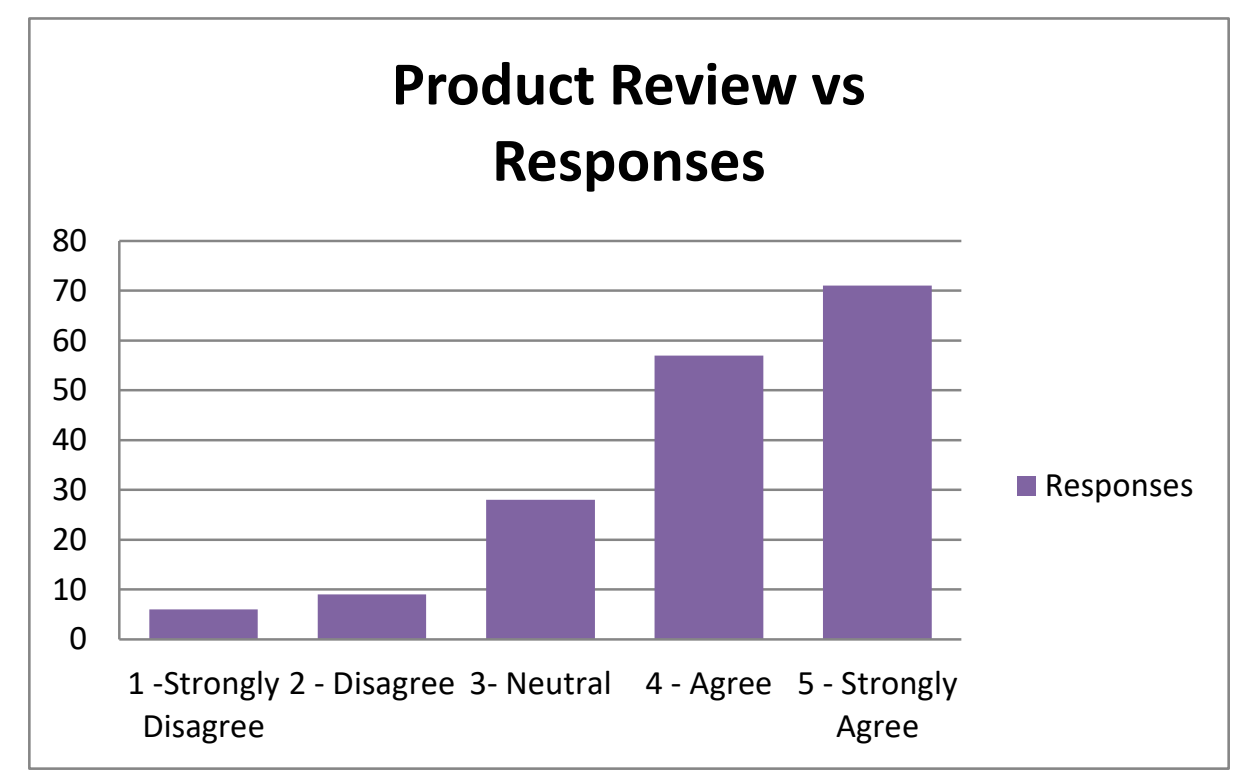

Source: Primary data

Interpretation: The above bar graph reveals about the people who are concerned with product reviews. About $71 \%$ people out of total i.e. $41 \%$ are concerned with the reviews about the product. The reviews up to an extent affect their buying behaviour.4\% doesn't bother about the reviews about the product. (Ezgi Akar, V.Aslihan Nair, 2015) It's totally depend on the customer intention influencing factors while most of the literatures focus on impact of consumer characteristics, product characteristics which is the impact on online purchase intention. 


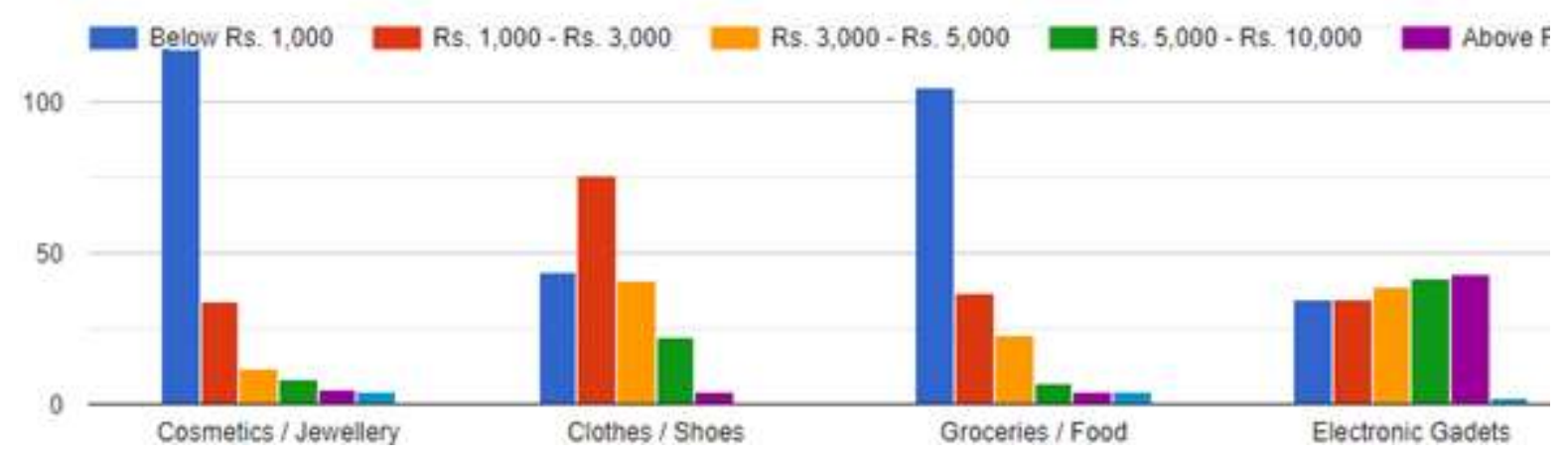

How much amount approximately spent on each product segment while shopping offline?

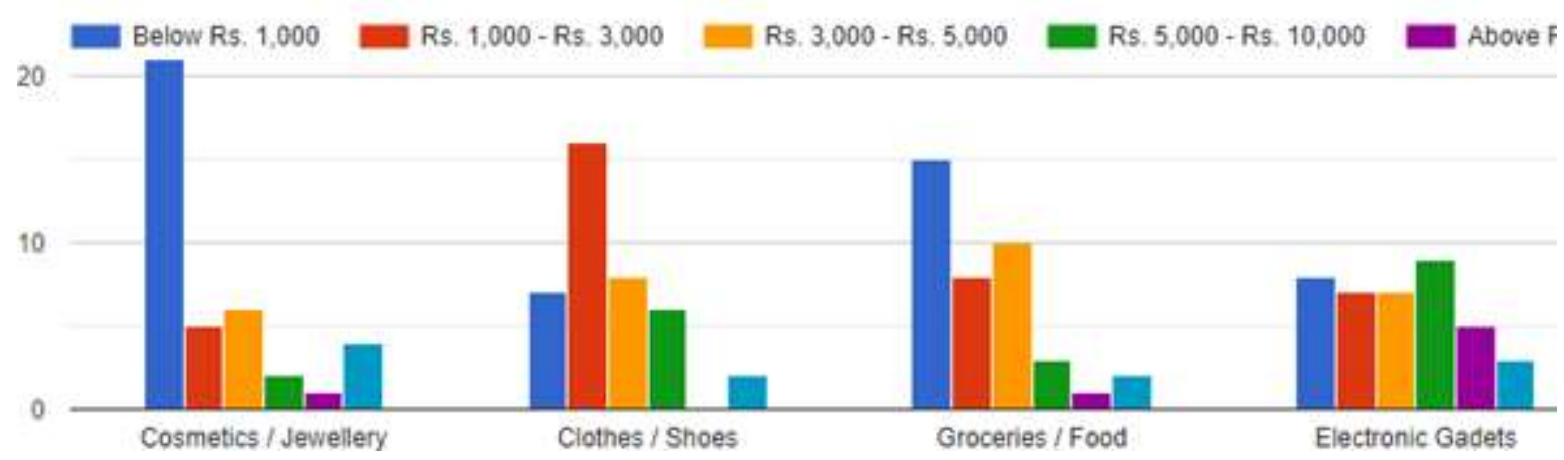

Interpretation: The Above graph tell us about the how much amount customer spend on each product segment while shopping in which most of them believe below 1,000 on Cosmetics/Jewellery, Groceries/Food, then 1,000 to 3,000 Clothes/Shoes rest on Electronic/Gadgets. (Mrs. Chitra Sharma, 2015) the attractive product \& segment in online platform are referred by the most of the consumers, accordingly they developed the product \& framing in the online platform.

\section{Share of Pocket: Offline Shopping}

Interpretation: The Above graph tell us about the how much amount customer spend on each product segment while shopping in which most of them believe below 1,000 on Cosmetics/Jewellery, Groceries/Food, then 1,000 to 3,000 Clothes/Shoes rest on Electronic/Gadgets. (Mrs. Chitra Sharma, 2015) the attractive product $\&$ segment in online platform are referred by the most of the consumers, accordingly they developed the product \& framing in the online platform.

\section{Delivery Service providers' preferences}




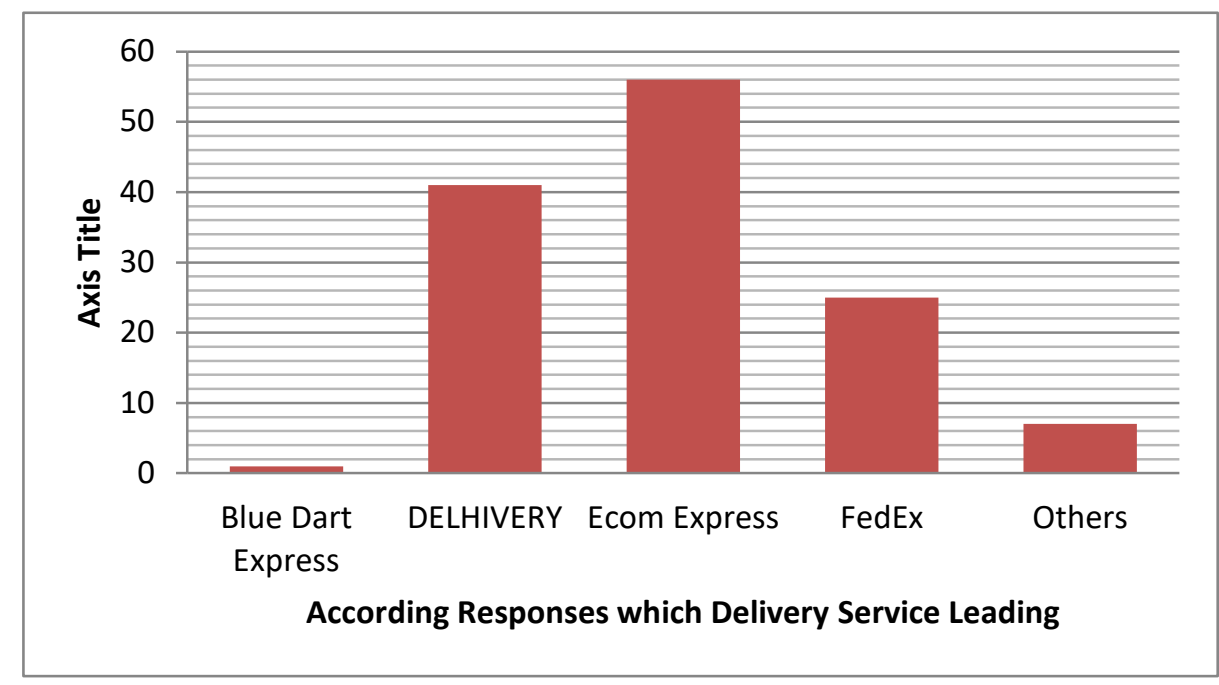

Source: Primary data

\section{Shopping Effectiveness vs Shopping preferences (Online/Offline)}

Interpretation: The Bar graph depicts about the effectiveness in both Online \& Offline Shopping. It reveals the fact that Offline shopping has more effectiveness than shopping Online. (Jifeng Luo, Sulin Ba, 2012) Literatures see the attributes towards the fashion which should be prioritized in retailers store which impact on effectiveness of the shopping in order to create a successful business as well as the consumer satisfaction toward the effectiveness online shopping.

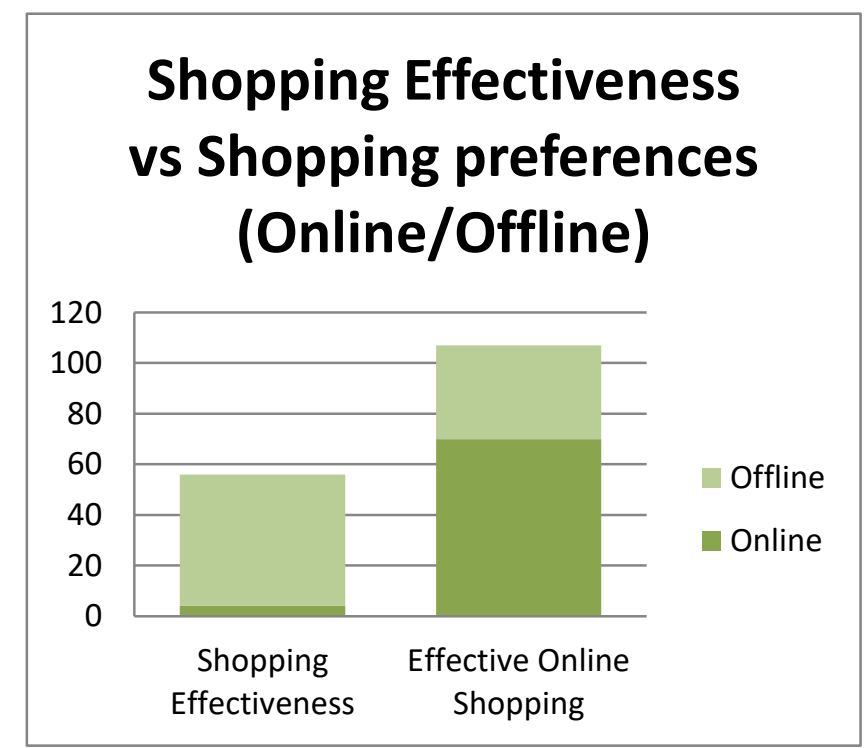




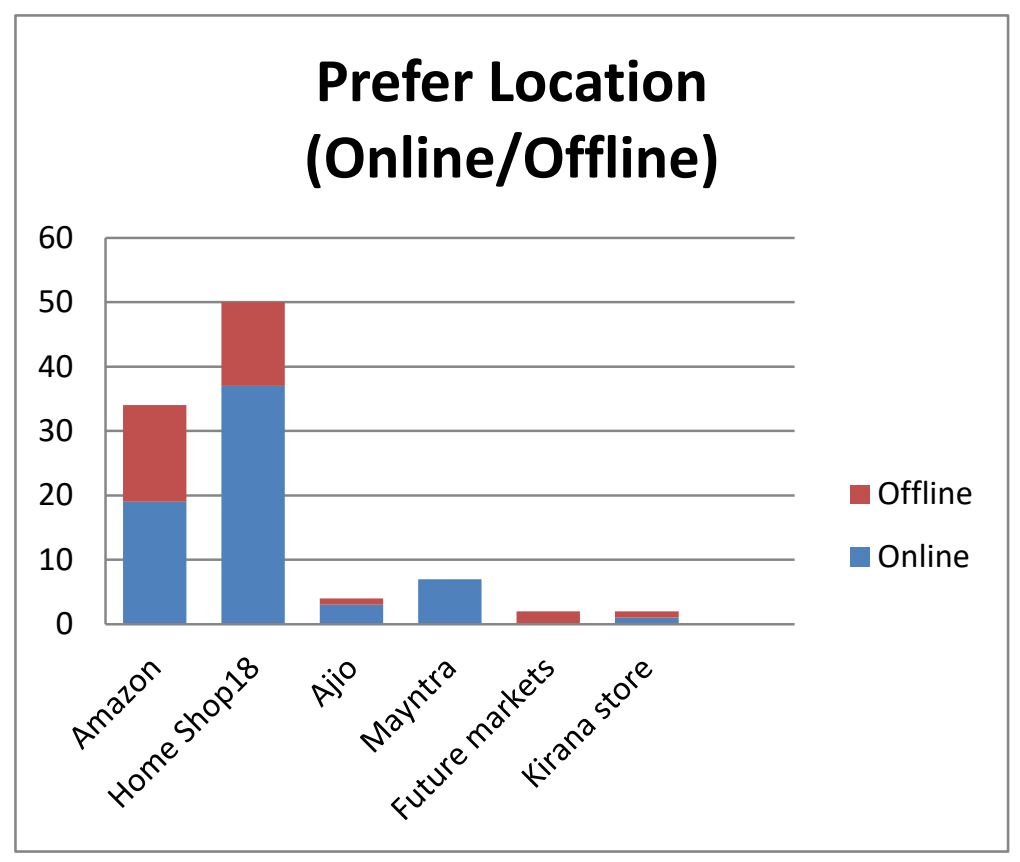

Interpretation: The Above graph tells us about the Online \& Offline locations. It reveals that most of the customers believe in Amazon while doing shopping online\& least on others. (Samrat Bharadwaj, 2019) the concept of Amazon in India with the competitor Flipkart and other retailer store depends on customer perception in which consumers want to order the product also based on strategies which company adopt or change continuously .

Product comparisons with the buying behavio
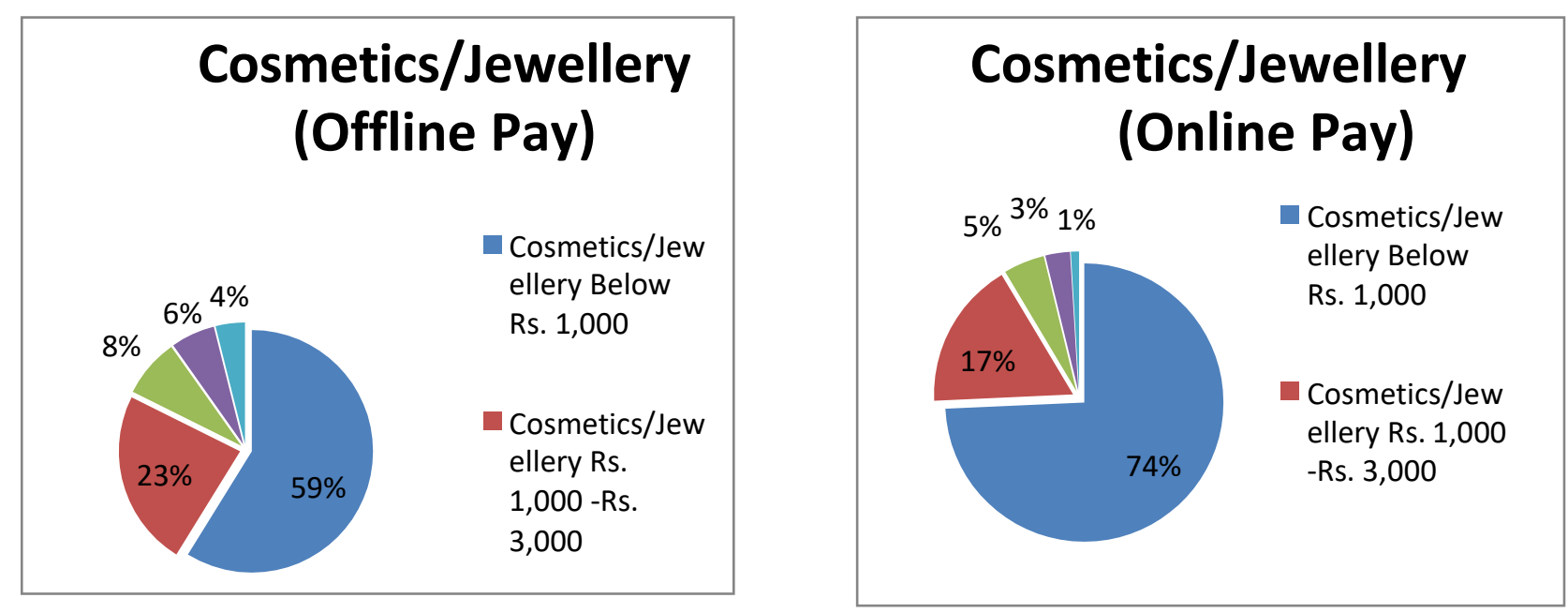
Interpretation: The above graph reveals about the online \& offline pay of various products and its range of cost. Now a day, People prefer online majorly for Clothes and footwear's since they can take their own time and choose their comfort outfit for them and footwear too. People usually prefer offline pay for Food \& Groceries because they want assurance for those for e.g. the way it's coming to the market, how well they've stored \& related things. In the case of cosmetic \& jeweler People go for online rather than offline pay which means it would not affect the decision cosmetics \& Jewellery, clothes \& shoes people tend to prefer more on online groceries more people prefer online same case in electronic \& gadgets \& higher price people prefer online reason heavy discount on credit card, less price people go offline \& local store. (Jyoti Meshram, 2016) as the continuously rises the trend in online shopping with the various segment in retailers store, where the fixed or variable type product get the more trend and attractive which make the more growing numbers of consumer to buy online products.

\section{One Time Delivery Comparison}

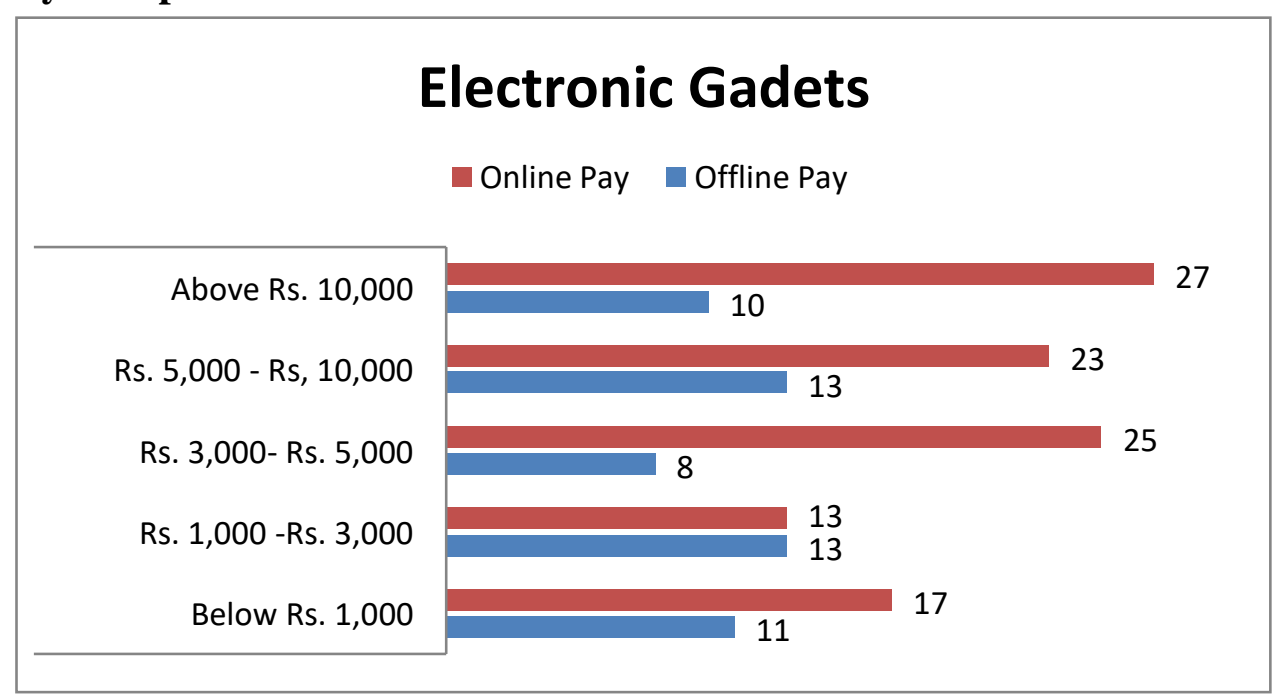

Interpretation: The Above graph reveals about the On-Time delivery comparison in between Online \& Offline. It depicts that about $76 \%$ People want On-Time delivery for Online shopping which shows the fact that there is an alarming need of on-time delivery in Online Shopping Mode. (Azharul Karim, Premaratne Samaranayake, AJR Smith, Saman K Halgamuge, 2010) To develop the OTD (On-Time-Delivery) improvement model researchers focus on the manufacturing organization based on intergraded data based as well as the business process to make order, transaction, and function mare faster then that the other logistics companies do.

\section{Gender Prefrence on Product Sensitiveness}

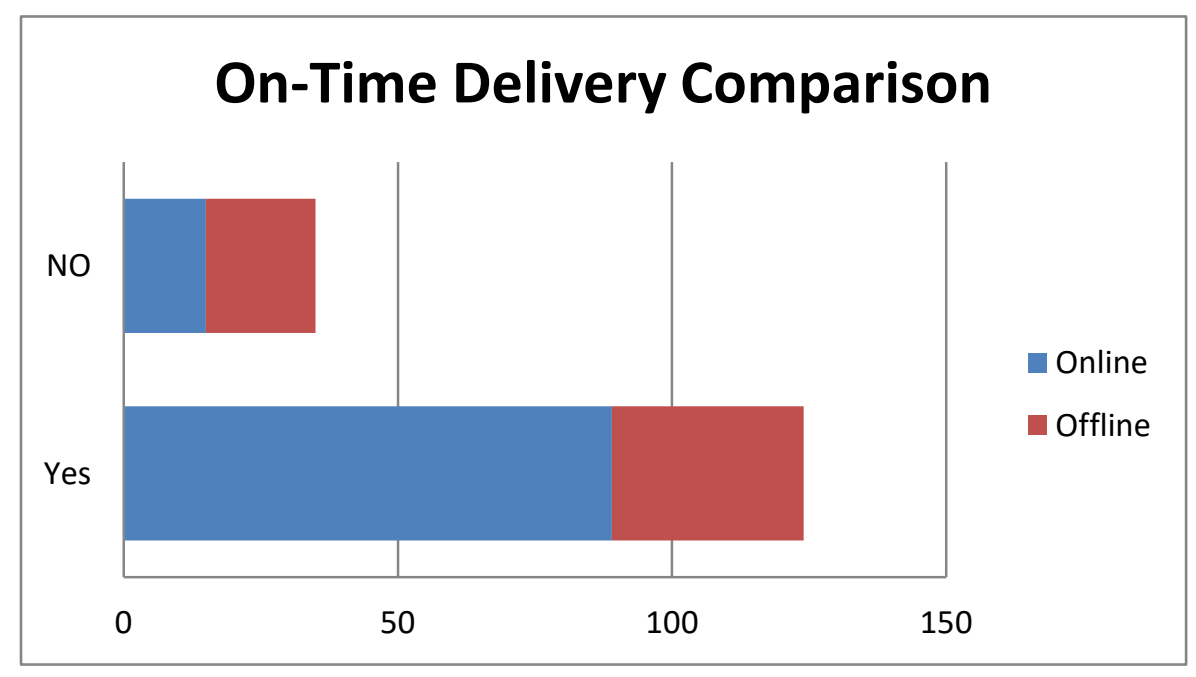




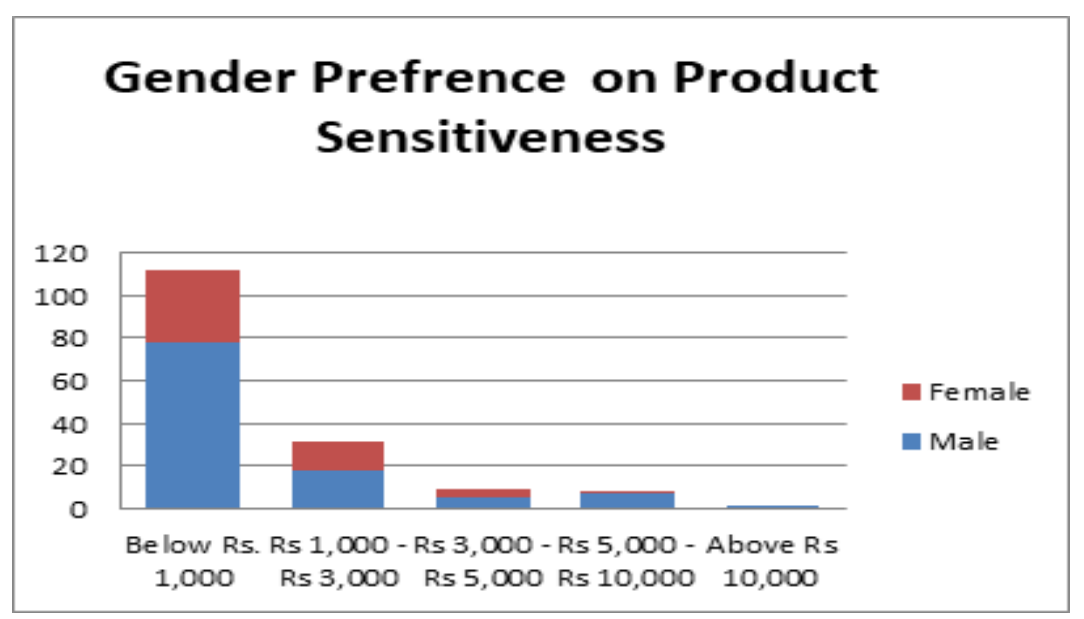

Interpretation: The Above graph based on gender preference on price whenever male buy the Cosmetic/Jewellery the prefer below 1,000 while female less prefer they even go higher price, similarly an another case they give responses based on price (Gyongyi Kovacs, Peter Tatham, 2009) It is clearly shows the effectiveness would come the more involvement of the gender responded in the form made the successfully prefer

\section{Product review vs Buying Behavior}

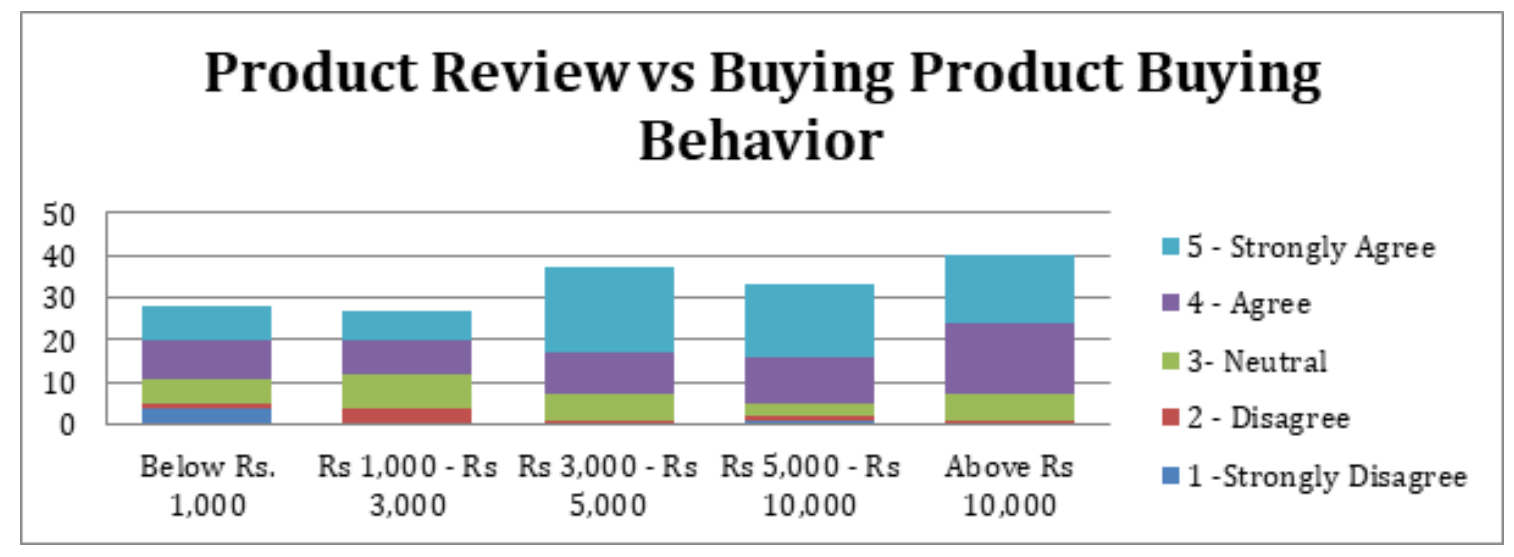

Interpretation: The Above graph tell us about the product review with the buying behavior in which most review with the more buying of the product which indicates that the those customer who aware about the product review after they gone through to buy \& satisfied with that product. (Efthynios Constantindies, Nina Isabel Holleschovsky, 2016) The importance of various product online customer reviews, which play an importance role to recommendation customer decision making process to buy product, literature has attention with the objectives of function toward these online platform reviews based on which customer adoption the preference and buy the product.

\section{Rank of factor vs Product Review}

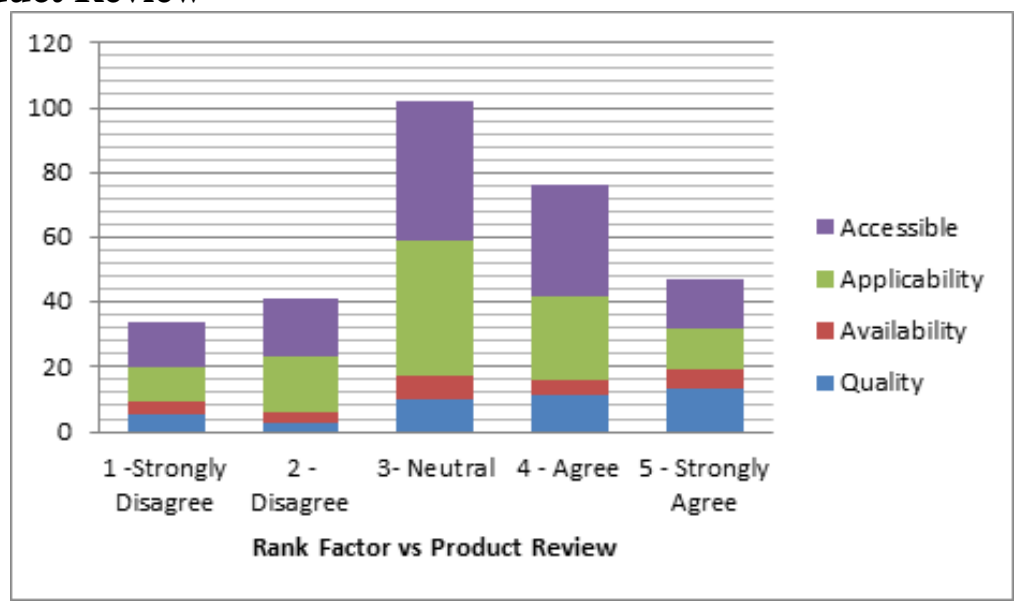


Interpretation: The Above line graph shows the buying behavior of customers based on the rank of factors. It is clearly evident that the customers think more about the applicability of the product and least with the quality which indicates that the they take decisions based on that product applicability to their life and they have a minimal care regarding the quality which much needed for use. (Kelley O'Reilly, Amy Macmillan, Alhassan G.Mumuni, Karen M. Lancendorfer, 2017) The purpose of the examine the factors affecting consumer review while buying the product and the decision making process, after the feedback collecting about the product which leading to an rises the product sensitiveness, and the use of electronic word-ofmouth, specially online product reviews also impacting on decision making process.

\section{Importance of On-time delivery}

Suppose, You ordered a product from Amazon/Flip-kart, which arrives late, does that late arrival of product affects you?

173 responses
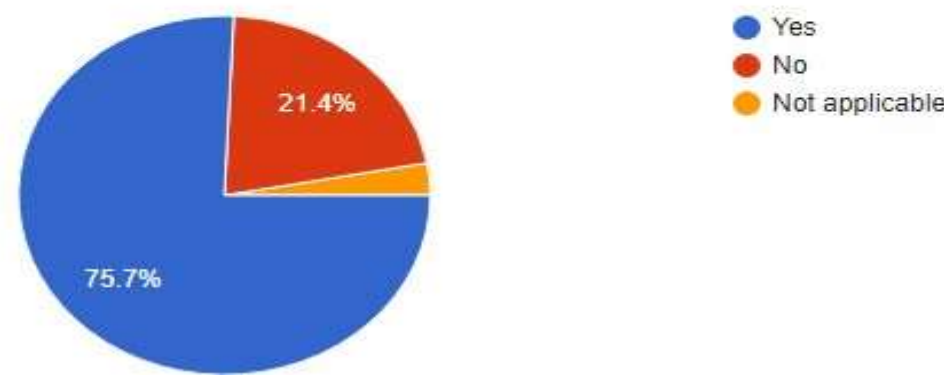

A delivery service that you always sticks for its on-time delivery, but if you get faster delivery from other vendor, would you like to switch the service?

173 responses

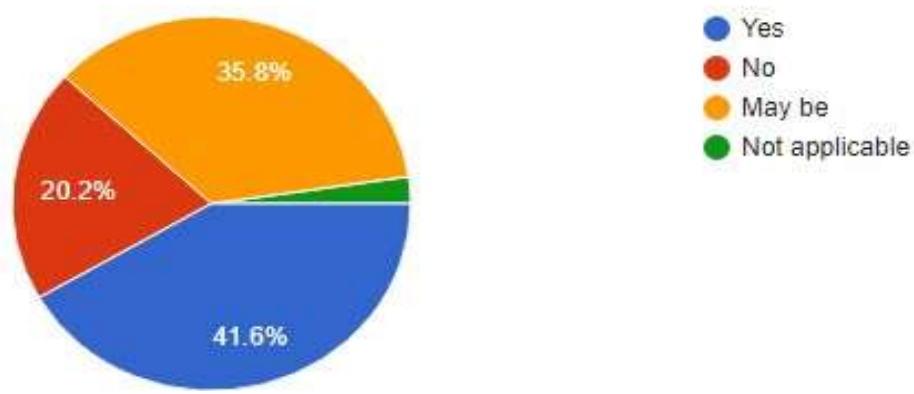

Interpretation: The pie-chart reveals that people are more frustrated regarding the late delivery. They really need a service which arrives on time because since many people prefer online shopping, they also have urgency to get their respective product for use. So, they really need an on-time delivery service. $75.7 \%$ People are really affected by late delivery services. (Amit Sarkar, 2018) the researchers said the major problem is when the accessibility is less \& $34.8 \%$ of the consumers have no offense when product or delivery arrival is late.

Interpretation: The above pie-chart shows alarming need of On-time delivery. Since the above graph is evident that People will switch the service if they get on- time delivery. About $41.6 \%$ people are nodding to switch the service where they get on-time delivery service. $36 \%$ of people are in the verge to switch i.e. they might switch or not. So, this graph really suggests needing the on-time delivery service. (Ige Pirnar, Mustafa Tanyeri, 2004) For the logistics outsourcing industry how gave better performance compare to the other industries they deserve the change in business as well as in an environment thorough LSQ 9logistics service quality) therefore, firms must be flexible enough to adapt new technology which rises customer demands \& supply. 


\section{Perception of Indian-e-commerce Industry}

Do you think Indian E-commerce Industry reached its height?

173 responses

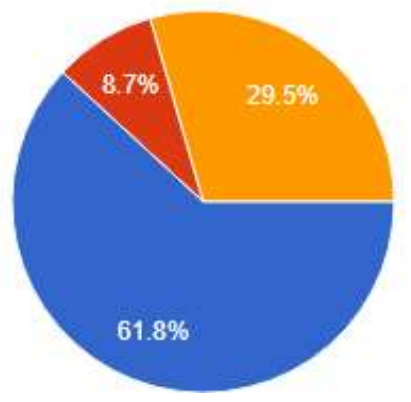

Interpretation: The above Pie chart reveals us that the customers think whether the E- commerce in India reached its saturation level. 61.8\% People are saying that the E-commerce has reached its supreme level but $29.5 \%$ are saying that it needs to be improved i.e. they're still didn't achieve its height. $8.7 \%$ saying that "not yet" and in fact the E-commerce industry needs to be improved. (Deboraah Libu Paris, Mahadi Bahri, Noorminshah lahad, Waidah Ismail, 2016) 65 primary searcher analyzed that the implementation phase has been done which result shows the major changes in E-commerce industries B2C and 49\% quantitative approach and $63 \%$ as the implementation phase which sufficiently shows the E-Commerce platform existing and appropriate implementation phases.

\section{Conclusion:}

The objective of this research paper were to 1) To analyze the effect of JIT and other techniques on Manufacturing and Logistics 2)Factors affecting Customer Satisfaction 3)Examine the effects of Logistics and Customer Satisfaction. After all the research has been conducted it has been reached the fact the hourly need of JIT Inventory system. The effect of JIT in Manufacturing \& logistics is so evident from our above graphs and their results. As it helps in reducing waste very effectively and efficiently, JIT inventory management not only helps the manufacturing methods and logistics but also helps in the co-operation \& commitment between suppliers and manufacturers. Our study also draws another conclusion that this Inventory Management practice will help to create a harmony and a close-bound relation rather than a clash or a competitive mind, which in turn increases their quality of service and the customer can enjoy to the utmost level.

While examining the factors of customer satisfaction and the degree of the satisfaction, most people are in need of speedy deliver of products rather than the accessibility \& quality of the product. This in turn underlines the need of JIT Inventory Management. Since this system reduces cost \& reducing lead time, companies response to customer needs increases. JIT is a simple and applicable philosophy to follow, with many benefits to reap. 


\section{Reference -}

1. Jie Yang, HongmingXie, Guangsheng Yu, Mingyu Liu, 2021. Achieving a just in time supply chain: the role of supply chain intelligence, University of Houston -Vistoria

2. Frimpong, Nadia, 2019. Customer Satisfaction in E-Commerce: The Role of Logistics Service Providers and E-Commerce Companies, School of Business Administration

3. TaweeratJiradilok, SettapongMalisuwan, Navneet Madan, and JesadaSivaraks, 2014.The Impact of Customer Satisfaction on Online Purchasing, Journal of Economics, Business and Management

4. Mai Ngoc Khuong and Ngo Qunag Dai, 2016. The Factor Affecting Customer Satisfaction and Customer Loyalty, International Journal of Innovation, Management and Technology

5. Khosla, Madhurima\& Kumar, Harish, 2017. Growth of E-commerce in India: An Analytical Review of Literature, IOSR Journal of Business and Management

6. Mark Huson, Dhananjay Nanda, 1995. The impact of Just in time manufacturing on firm performance, Journal of Operations Management

7. Rajab AdullahHokoma, 2016. A Survey Investigation of Just in time Implementation and tis implications for Management in Four key Industries, University of Tripoli - Libya

8. Allan F. Scott, James H, Macomber, Lawrence P. Ettkin, 1992. Just in time Job satisfaction: Some empirical results, Production and Inventory Management Journal

9. Vikas Kumar, Dixit Garg, and N P Mehta, 2004. Just in time practices in Indian Context: A survey, Journal of Scientific \& Industrial Research, National Institute of Technology - Kuruksherta

10. Vikas Kumar, 2010. Just in time Based Quality Management: Concepts and Implication in Indian Context, YMCA University of Science and Technology - Faridabad

11. MadhurimaKhosal, Harish Kumar, 2017. Growth of E-commerce in India: An Analytical Review of Literature, IOSR Journal of Business and Management, University of Delhi

12. Rajendran, Shalini \& Wahab, Siti \& Ling, Yeow \& Yun, Lim, 2018. The Impact of Logistics Services on the E-Shoppers' Satisfaction, School of Business Administration

13. Vivek S Kanade, 2019. Review of Literature online \& offline consumer buying behavior, Research gate publication $/ 331175334$.

14. Miniard, Pan, 1990 \& 2007. Literature review of online purchase intention marketing, Ukessays publisher

15. Nishad Nawaz, M Phil, Wafa Ms, Ali Yaqoob, 2014. A study of consumer preferences for E shopping with reference to Bahraini consumers, Research gate publication / 271132440.

16. Ezgi Akar, V.Aslihan Nair, 2015. A review of literature on consumers' online purchase intentions, Research gate publication /286624349.

17. Charles Dennis, Bill Merrilees, Chanaka Jayawardhena, Len Tiu Wright, 2019. Quality in higher education from different perspectives A literature review, Research gate publication

18. /317017897.

19. Mrs. Chitra Sharma, 2015. Indian Journal of Applied research (IJAR) recent issues, worldwide journals / 1428502066.

20. Parisa Dolati Neghabadi, Karine Evrard Samuel, Marie-Laure Espinous, 2018. Systematic literature review on city logistics overview classification and analysis, Research gate publication / 326387987.

21. Gyongyi Kovacs, Peter Tatham, 2009. Humanitarian logistics performance in the light of genderness Research gate publication /46419452.

22. Arlina Nurbaity Lubis, 2018. Evaluating the customer preferences of online shopping demographic factors and online shop application issue-7066, AbAcademics publisher

23. Jifeng Luo, Sulin Ba, 2012. The Effectiveness of online shopping characteristics and well Designed websites on satisfaction, Research gate publication / 281763910.

24. Samrat Bharadwaj, 2019. The war between Flipkart and Amazon India A study on customer perception, Research gate publication /333747012.

25. Jyoti Meshram, 2016. Study of Impact of Online Shopping on conventional shopping methods by today's youth with respect to clothing and accessories, Research gate publication/ 309608591 .

26. Azharul Karim, Premaratne Samaranayake, AJR Smith, Saman K Halgamuge, 2010. An on- time delivery improvement model for manufacturing organizations. Research gate publication 1235009079. Abdullah Al-Mamun, Muhammad Khalilur Rahman, S D Robel, 2014. A critical 
Review of Consumer's sensitivity to Price managerial and Theoretical Issues, Research gate publication

27. $/ 265598350$.

28. Gyongyi Kovacs, Peter Tatham, 2009. Humanitarian logistics performance in the light of gendernces, Research gate publication /46419452.

29. Efthynios Constantindies, Nina Isabel Holleschovsky, 2016. Impact of Online Product Reviews on Purchase Decision, Research gate publication / 302973824.

30. Kelley O’Reilly, Amy Macmillan, Alhassan G.Mumuni, Karen M. Lancendorfer, 2017. Factors Affecting Consumer's Online Product Review use, Research gate publication / 320404445.

31. Amit Sarkar, 2018. Consumer satisfaction on Amazon online shopping, Dept of Management studies, International Journal of Information \& management.

32. Ige Pirnar, Mustafa Tanyeri, 2004. Marketing Trends for logistics, Research gate publication

33. $/ 273462446$

34. Shadi AlZu'bi, Abdalraheem Alsmadi, Sokyna Qatawneh, Mohmoaud Al-Ayyoub, 2019. A Breif Analysis of Amazon Online Reviews, Research gate publication / 337974148.

35. Sayed Mohammad Tariq Zafar, 2011. Value Proposition and Functional Quality Dimension Enhance Customer Loyalty A study of Consumer Behavior at EasyDay Retail Store, Research gate publication/ 290428839.

36. Philipp Wetzel, Erik Hofmann, 2020. Compensation and incentives, Practice vs theory, The Journal of Finance, 43:593-616.

37. Md Shamimul Islam, 2019. A literature review on green supply chain management Trends and future challenges, Research gate publication /328685059.

38. Deboraah Libu Paris, Mahadi Bahri, Noorminshah lahad, Waidah Ismail, 2016. Systematic literature review of e-commerce implementation studies, , Research gate publication / 306167259 